\title{
Structuring a course service for developing the learning digital skills of university students in Fribourg
}

\author{
Hervé Platteaux ${ }^{1, *}$, Emmanuelle Salietti ${ }^{1}$, Laura Molteni ${ }^{1}$ \\ ${ }^{1}$ Centre NTE DIT, University of Fribourg, Boulevard de Pérolles 90, CH - 1700 Fribourg, Switzerland
}

\begin{abstract}
This paper is an analytical description of a course service that aims to improve the digital skills of university students. This innovation is part of the Digital Skills program of Swissuniversities (P8) and is currently developed in Fribourg (collaboration between the University and the HES-SO Fribourg). It is more a course service than a course because we propose: different modalities (a 3 ECTS course in Autumn and a self-learning course all year long), flexibility of contents (adaptation of the digital skills to be developed), flexibility of the course opening (students from all faculties and all BA years) and communication actions on the course in the institutions. We first analyze why a digital skills development is important today and what the main learning objectives are. A second part shows, with the help of surveys on the students' learning needs in digital skills, why flexibility has become a key element in the design of our service. A third section describes how the construction of a detailed competence framework facilitates the definition of learning resources that are aligned with the targeted digital skills and then enables the implementation of content flexibility. Finally, we describe the course system structure itself.
\end{abstract}

\section{Introduction}

Currently a series of projects are underway as part of the Digital Skills program of Swissuniversities (P8). In this context, we think that it is appropriate to present here the ideas behind a course whose main objective is to help the development of students' digital skills, which is conceived as a service system and which is currently being developed in Fribourg as part of a collaboration between the University and the HES-SO Fribourg [1].

In the Digital Skills Project of Fribourg, various courses have been launched and more will be opened in the future. It would not be adequate to work with a common structure to design and implement all the different courses, as they target very different publics (teachers and students, from BA1 to $\mathrm{PhD}$ ), different learning subjects (very focused or very broad), different timings (from half a day workshops to 3 ECTS courses), etc.

Therefore, this paper focuses on a specific course which is an innovation to meet the needs of students to improve their learning skills through the development of their digital skills. The authors report here on fundamental elements of its design. The course is now beginning to live, in different modalities, so this is not the time for a large formative evaluation of its efficacy. However, we will provide some results that validate the foundations of the wanted system.

This paper is thus an analytical description of the innovation pursued to design and implement a course service that aims to develop the digital skills of BA students. Through this description, we adopt a pedagogical rather than a technological point of view, as it reflects the core of the innovation brought by this course service.

\section{It is now time for digital skills in higher education}

Let us look at the reasons for our course system. We underlined in the introduction that the current context of the P8 program of Swissuniversities about Digital Skills [2] is an appropriate time to develop such a service. Like many other higher education institutions in Switzerland, the university and HES-SO of Fribourg want to participate in this joint federal effort for the development of digital skills in higher education. This effort is part of an overall trend, on a more global scale, that is taking place in society and in the formal education system. One can cite, for examples, the EU "Digital Education action plan (2021-27)" [3] and the action of the DQ institute "Common framework for digital literacy, skills and readiness" [4].

\footnotetext{
* Corresponding author: herve.platteaux@unifr.ch
} 
But it was necessary to change the general mindset to make everyone aware of the need for such courses. For example, concerning the worlds of secondary schools and of higher education, one can rethink to the debate, twenty years ago, about the "Digital natives" notion [5] saying that the new generation of students are used to digital technologies and use them naturally for learning. Later it was shown that the new generation is not so experienced in digital skills for learning [6] [7] and, also, that universities can play a crucial role to develop students' digital literacy by "developing practice through authentic academic tasks" [6]. Higher education formal institutions can demonstrate the importance of these skills to students and offer trainings to help their development. Today the situation has evolved towards a better understanding of the overall impact of digital technologies on higher education [8] and of the positive impact of students' digital skills on their academic success and their professional future: "The development of the literacy level of students and their digital competence is crucial for improving the effectiveness and efficiency of the learning process as well as for the adaptation of students to the dynamically changing labour market" [9].

It is now known that digital skills have a positive impact on the students' success during their studies and the development of digital skills is seen as crucial from a socio-economical perspective. For example, because "digital transformation poses critical challenges to organizations" [10], companies have to develop innovative digital business models and, to do so, they have to develop activities with their employees such as "systematic trend scouting; evaluation and road mapping of trends; prototyping and pretotyping; design thinking; internal hackathons or idea contests; and setting-up strategic venture funds to support start-ups" [10] where many digital skills, and other types of skills, are necessary. Also, the deep impact of Covid-19 on the world of work shows the importance of the skills needed by all those who had to turn to telework [11].

The innovation we describe in this paper is part of this change process: universities want to play a role in the development of digital skills and they organize trainings and courses to help their students in a lifelong perspective.

\section{Pedagogical foundations of the course system}

We will now describe the pedagogical foundations of the course system, as they take us directly into its objectives and principles. The aim of the project is also much more a pedagogical innovation than a technological innovation. Having the pedagogical foundations in mind should help the reader to understand the structure of the course system explained in section 4 .

\subsection{Global learning objectives}

The main global learning objective of the course system is about enabling students to develop their Personal Learning Environment (PLE) and we refer here to what Atwell wrote when discussing first concrete ideas about what PLE might be: "This is not so much a technical question but an education one" and "more of a new approach to using technologies for learning" where "The idea of a Personal Learning Environment recognizes that learning is continuing and seeks to provide tools to support that learning. It also recognizes the role of the individual in organizing their own learning." [12].

Therefore, with our system, we want to facilitate the learning of the students following a cursus at university. It is about facilitating the learning activities that students have to perform during their courses. In the Digital Skills project, we want in particular to provide the students ways to get "tools" helping this work: 1) digital tools such as web and software tools (technological components of PLE) and 2) knowledge and know-how about methods and features to be used with digital tools (educational components of PLE). This is the core of the service: supporting the digital aspects of students' regular learning activities.

To be concrete and clear, we give a list (not exhaustive) of those learning activities. During their studies, either requested by course teachers or done informally, students are searching for information (in particular bibliographical references), producing working documents (lecture and reading notes; different types of graphics) in order to analyze information (qualitative or quantitative), writing academic works (thematical summaries or synthesis; seminar papers; BA and MA thesis), making oral presentations by preparing digital visual documents, managing their collection of documents, communicating and collaborating (with teachers, with their colleagues in team activities), etc.

Even if our overall aim is to help students develop their PLE, we mainly "limit" this support to the digital aspects of PLE (assembling of digital learning technologies and associated usage skills) because we are developing this help in the framework of the digital skills project. However, we see this action in the wider perspective of PLE because we want students, when using our system, not to reject any information and/or tool because it is not strictly and totally related to the digital world. We don't want a hermetic barrier in the system, and in the minds of students, between digital and non-digital skills. Such a barrier is artificial and would decrease efficacy of learning in the system. An example linked to the learning activity "Research of bibliographical information" will illustrate this point. The starting step of this learning task is to define correctly the thematic of the bibliographical research. It means at least to create a list of keywords, to think about the extension of the future research and about the type of document (general or detailed?) to be produced with the help of the searched bibliography, etc. This is not at all 
a digital skill. Digital skills intervene when students begin the next steps of the activity: defining the online research tools that will be used for the research (which scientific bibliographical database?) and manipulating the database features both to create-refine a keyword request and to navigate in the information linked to all the references proposed by the database. But if students have no idea how to define their thematic and translate it into keywords, their digital database skills are useless.

\subsection{The need for a competence framework}

The previous section showed that our central objective is to make our public learn "her his job as a student", from a methodological and tools' point of view with a special focus on digital skills and tools. In order to build on the list of learning activities provided earlier in this text and to transform this list into a real competence framework of related digital skills, we looked through different recognized frameworks, especially DigComp 2.1 [13] of the European Commission and the guide of the JISC team [14], and through research works, especially the literature review of Van Laar et his colleagues [15]. Applying them to the context of the university in Fribourg, we obtained a digital competence framework for students with a hierarchical structure of five main competence groups: 1) Computing culture $\left.{ }^{1}, 2\right)$ Information literacy (composed of 3 main competences and 9 sub-competences), 3) Creation of digital contents (composed of 5 main competences and 10 sub-competences), 4) Communication and Collaboration (composed of 6 main competences and 16 sub-competences) and 5) Problem solving (composed of 6 main competences and 13 sub-competences) [16].

To continue this analysis of our course system, it is useful to give a definition of the notion of competence ${ }^{2}$ : One can say that a person has a competence when he/she can mobilize knowledge to perform an activity in a given situation [17] [18] [19]. Let us add a few concrete examples to illustrate the two notions of learning activity and of learning situation used in this definition ${ }^{3}$. Taking notes is a typical learning activity of students (from the group Creation of digital contents) and evaluating bibliographical documents is another one (from the group Information literacy). Attending a course and reading scientific articles are typical learning situations. We can easily understand that performing the same activity in two different situations develops or requires different competences: for example, taking notes during a course and taking notes while reading a scientific article.

The development of a competence is therefore facilitated when the students are placed in a situation and asked to perform an activity by mobilizing knowledge. Atwell says [12] that the development of the PLE results a lot of unformal learning situations. The digital skills of our students come largely from their informal exploration of web applications, for example social networks, on their own or with their friends. The role of our course system is thus to organize complementary formal learning situations to develop their digital learning skills [20] to be mastered in the context of higher education. Therefore, a competence framework can help implement the pedagogical mediation that students need to develop their digital learning skills and teachers need to support this learning development. The competence framework helps the pedagogical mediation both 1) for the communication, about the competences, happening between students and teachers during learning activities and 2) for the more psychocognitive aspects of the learning activities [21]. The competence framework can be seen as the skeleton of the pedagogical scenario needed to develop the digital skills.

A concrete example will perfectly illustrate the communication aspect about digital skills. We need to move students beyond the state of communication where they are only able to say about their digital skills: "I know to use Word", and similar phrases for other digital skills. If they remain in this state, they will encounter a series of misunderstandings and problems during their studies. Students are true when they say they know to use Word. They know to use Word in the learning situations that they experienced (for BA students, mostly the ones of secondary school) and this means that they know how to use certain types of Word features in order to write certain types of documents. But most of them do not know how to use the Word features to enhance the scientific structure of long documents, with tables of contents and of figures, and a documented argumentation with reference citations and a bibliography, which requires the addition of a few plug-ins. They have to discover, explore and develop the digital skills, linked to the use of Word, that must be mastered in the learning context of higher education. Universities need to communicate to their students the framework of these digital skills to help them in this development. To do this, the competence framework they use must specify the exact learning activity and situation in the description of the different competences. We explained in a previous work [21] that this description process of digital skills is the phase of contextualization where a generic competence (such as "The use of Word") is transformed into a real specific student competence (achieved or to be developed) which takes into account their

\footnotetext{
1 This competence group is the learning objective of another course. We are then not detailing it in the present paper.

${ }^{2}$ We are using in this text the two notions of "skills" and "competences" as synonyms which is not right, from a scientific point of view. We decided to proceed so in this text because it starts with the context of the project "Digital skills" from Swissuniversities and needs now a definition and explanation for the notion of competence. If the reader wants, he she can refer to our blog article https://nte.unifr.ch/blog/2018/05/07/competence-skill-capacite-aptitude-vous-vous-y-retrouvez/ to find the differences between the two notions.

${ }^{3}$ We will further explain the notions of mobilization and of knowledge in a later paragraph.
} 
learning activity and their learning situation (such as "The citation of bibliographical references in Word with Zotero for a seminar work").

Let us now enter into the more psycho-cognitive aspects of competences, deeply linked with the notions of mobilization and of knowledge that are present in the definition of competence, which was given earlier. In the previous work we cited already [21], we explained that these psycho-cognitive aspects of a competence can be used to describe the digital skills to specify exactly what knowledge and know-how do the students have to master to perform a specific activity in a specific situation. If a teacher knows these components of a specific competence, he'she really knows the learning objectives to be achieved and can better design learning activities and resources which can be proposed to students in order to develop this specific digital skill. Let us considerer a concrete example: a student has to make a bibliographical research of scientific publications. To perform this task efficiently, he-she must know that scientific bibliographical databases are existing. Otherwise he she will look in Google only. Then he-she also must be aware of the differences between the two tools: Google is not a scientific database but a general web search engine; a scientific database is based on systematic principles (exhaustivity, thesaurus, etc.); etc. Then he-she must know how to enter a keyword request in a database, how to evaluate the answers of the database (proposed articles), etc. Other steps should be given here to detail this description completely. However, we can see with the given description how the model of Paquette [22] can be used to obtain a systematic description of such psycho-cognitive aspects of a competence. For him, there are 3 types of knowledge (concepts, procedures and principles) and 4 levels of mobilizations (reception, reproduction, creation and selfmanagement). In our example, different concepts must be known at a reception level (scientific databases, general web search engine, keyword) but also procedures (keyword request, evaluation of proposed articles) and a principle (systematics of scientific database). We can understand also that the keyword request procedure must be mobilized at another level (reproduction) and the concept of keyword must be mobilized at the level of creation (when the student creates the list of keywords). Even if we stop this description here, we see how a competence, linked to a learning activity and a situation, can be explored systematically with this model and make teachers able to build a course scenario from this exploration.

\subsection{One student, one learning need}

We want to ensure that the development of digital skills can start for any student as soon as they enter a university course and that the course is therefore open to all undergraduate students. Concretely it means that the course is transversal to the training offer of Faculties and that students can register for the course when they enter a BA cursus (year 1 of BA) but also later (years 2 or 3 of BA) if they could not attend the course during year 1.

We took this decision after a survey in our student population concerning digital skills. We know that students entering university have experienced various digital tools during their past learning experience. But what experience do they have concerning the exact competences of a university competence framework? We wanted to investigate this question to better define the course system features that will answer the learning needs of our students with the competence framework as a target.

Even if our competence framework was not finished in 2019, we were knowing its main lines and we decided to make a survey in December 2019 in the students' population. An online questionnaire was proposed to all the students of the university of Fribourg (about 10'500 in total). Among them 922 entered the questionnaire. Three very short questions were placed at the beginning (Are digital skills important? Do you need to develop your digital skills? Will you invest time to develop your digital skills?). 755 students answered the three questions: $90 \%$ said that digital skills are important; $77 \%$ that they have to develop such skills and $63 \%$ that they will invest time to do so. Then students were asked if they wanted to enter a second part of the survey. About 550 students entered the second part where questions were general about digital skills or focused on a group of digital skills. About 500 to 540 students answered the general questions and about 400 to 450 students answered the focused questions. We would like to insist here on the fact that the results given below are only indicative of trends. The number of students who answered (about 4 to $5 \%$ of the total population in the second part of the survey) is quite sure not enough to be representative. In particular we will not give here any results where the students are grouped according to their faculty. There are too many different curricula in a single faculty and there is no doubt that a few of them are not present in our data. Instead, we will look at the results where the students are ranked according to the year of study in which they are enrolled (BA1 to BA3, MA1 and MA2, PhD1\&2 and PhD3\&4). Among the students who answered questions in the second part of the survey, we have 301 students in BA, 188 in MA and 50 in $\mathrm{PhD}$. Then, we think that the results given with this classification are giving a feeling of what a BA, MA or PhD student feels about our questions.

In the second part of the survey, one general question was asking the students "Do you feel well prepared for digital skills?". The graphic below (cf. Fig. 1) shows the given answers with a scale: 1 corresponds to totally disagree and 5 to totally agree. Figure 1 shows that 20 to $30 \%$ of students answered with 1 or 2 . This population feels then not well prepared. Then 30 to $40 \%$ of students answered 3 . This population feels then not enough prepared. Then only 15 to $30 \%$ of students say they are well prepared. Finally, 10 to $15 \%$ of students answered "I 
do not know". This population does not know how to assess their level of preparedness. In fact, for BA and MA students, we do not see a big difference between the different years of study that students are attending.

$$
N=533-12.2019
$$

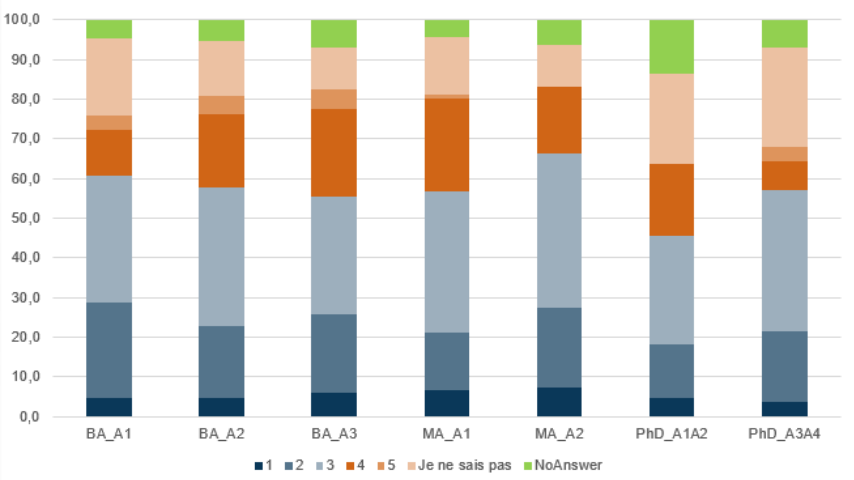

Fig. 1. Answers of the students to the question "Do you feel well prepared for digital skills?" (Survey of 12.2019)

If we have now a look at focused questions, Figure 2 shows answers for the questions about the group "Information literacy" and Figure 3 about the group "Collaboration" (groups were not named in the questionnaire but only numbered). In the group about "Information Literacy", students had to position themselves, using the same 5 level scale as in the general questions, for a series of sub-competences and for two questions: "How do you master the competence?" and "How do you consider the competence useful for your studies?". Sub-competences for the "Information literacy" group were for example: "I can look critically at information on a web page", "I am able to use digital bibliography management tools", etc. (5 items). For the "Collaboration" group, sub-competences were for example: "I am able to use text treatment tools for collaborative writing", "I know how to profit from online social networks services to manage my professional profile", etc. (9 items). The answers show large differences in the student population, depending on the competence group considered. Figure 2 shows that students express a high level of mastery for the competences of the "Information literacy" group, regardless the year of study that they are attending. For all the year of study, at least $60 \%$ of the students, and until $80 \%$, answered with the levels 4 and 5 of mastering. For all the years of study, $80 \%$ to $90 \%$ of the students also answered with the levels 4 and 5 of usefulness for this group of digital skills. For the group about "Digital Collaboration", Figure 3 shows that, in all the years of study, there are two important groups in the total population: students with a low mastery level are always $30 \%$ or more and students with a high mastery level are always 30 to $50 \%$. Also, for the usefulness, students are much more hesitating for this group of digital skills. In all the years of study, there is always $50 \%$ of students at least who are convinced of their utility but there are always 10 to $20 \%$ of the students who consider the contrary and also 5 to $15 \%$ of the students who do not know how to evaluate their utility.
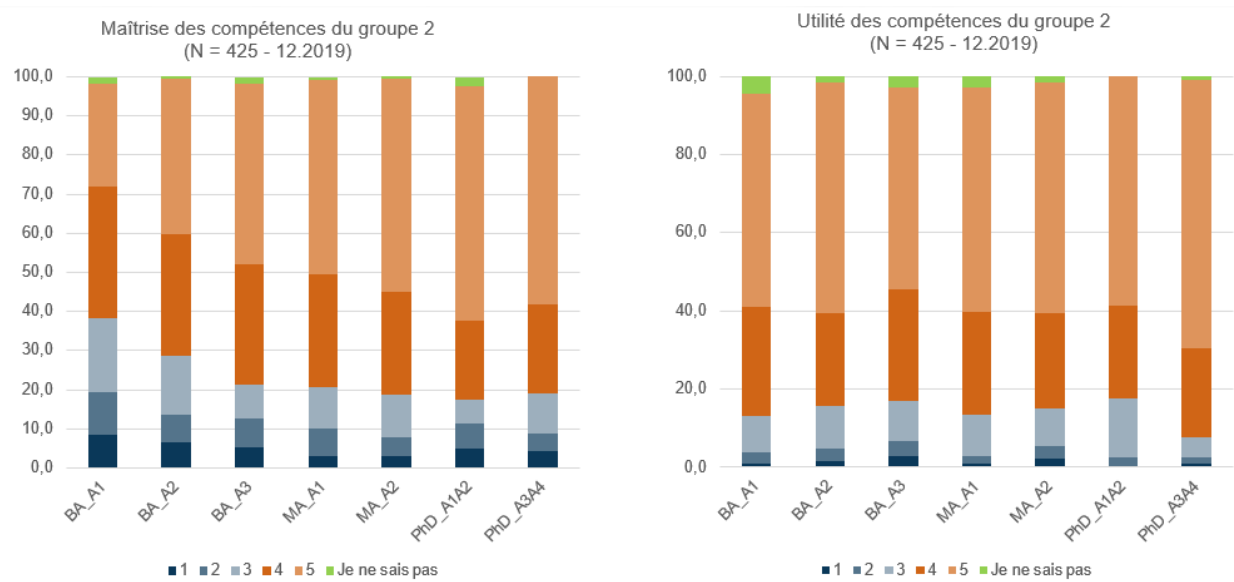

Fig. 2. Answers of the students to mastering and utility of skills for Information literacy 

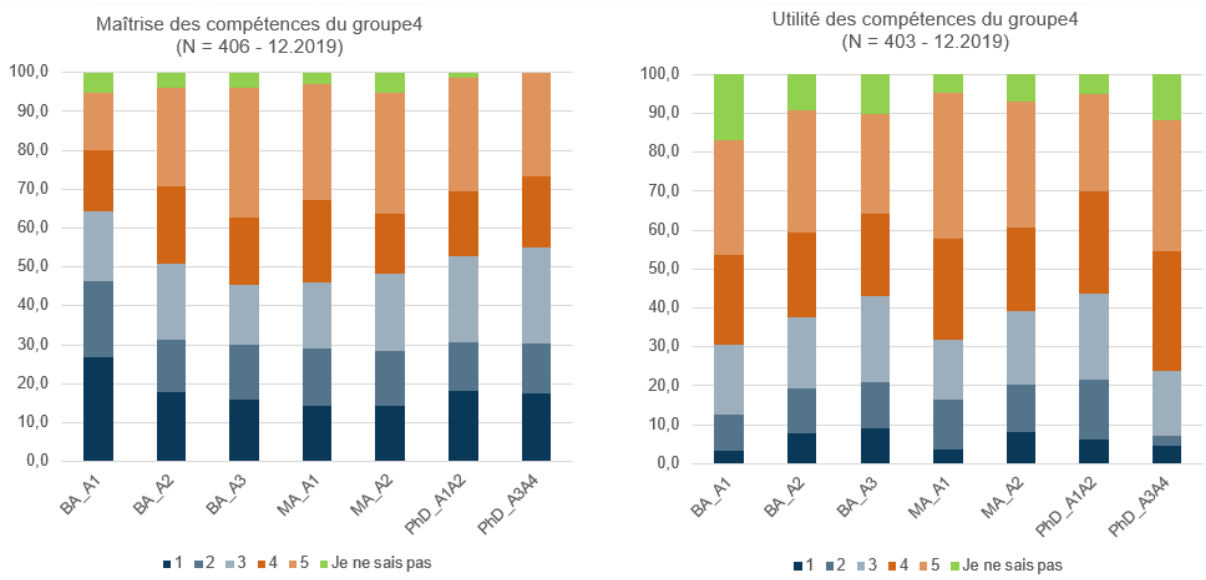

Fig. 3 Answers of the students to mastering and utility of Collaboration digital skills

These results, both for the general and focused questions, showed that our course system has to offer flexible features: it has to be opened for students in year 1 of a BA but also in years 2 and 3; it has also to offer flexible contents. This is why we cannot consider just organizing a course, opened in a specific cursus with the same contents for all the students who are enrolling. We must set a course service open for all the students in BA of all the faculties and with possibilities, when they enroll, to evaluate their personal digital skills and to deepen them according to their individual priority learning needs.

This year, 66 students enrolled in our course: 7 students began their university studies in $2021(11 \%$ of the population), 24 in 2020 (36\%), 15 in 2019 (23\%), 8 in 2018 (12\%), and 5 in 2017 or earlier (8\%). We miss the information for 6 students. Also, 2 students are now enrolled in a MA and the 64 other students are in a BA. We cannot make a strict association of the year where students entered university and their year in the cursus. However, we can say from these figures, with a high level of certitude, that students do not enroll directly in the course: $59 \%$ of our class are at university since one or two complete years. This is certainly partly due to the fact that our course is a very recent offer at the university and is therefore not well known. But we also assume that many students have to spend some time at university before they realize 1) the importance of digital skills in their studies and 2) what digital skills they have to develop. We have then here a confirmation of the flexible openness of the course, for the BA students, that we have to offer.

Let us now have a look at other results concerning the contents of the course. The sets of questions in our 2019 survey have evolved, been completed and refined and have allowed us to construct two types of tests. At the beginning of the course, students self-position individually by answering "Yes", "No" or "I do not know" to questions like: "You are able to..." or "You know and practice this step for doing this task?". There is a list of questions for each of the four main themes of the course. Here below, we calculated the proportion of Yes that all our 66 students answered this year for each theme.

- Theme 1 (Information literacy, Research and management of bibliographical information): ○ $\quad$ average $=38,3 \% ; \mathrm{SD}=32,7 \%$

- $\quad$ Theme 2 (Creation of digital contents, Visual contents for an oral presentation): ○ $\quad$ average $=67,3 \% ; \mathrm{SD}=19,0 \%$

- $\quad$ Theme 3 (Creation of digital contents, Writing an academic document): - average $=80,9 \% ; \mathrm{SD}=14,6 \%$

- Theme 4 (Creation of digital contents, Note taking) and (Information literacy, Data processing): ○ $\quad$ average $=32,6 \% ; \mathrm{SD}=16,5 \%$

A big difference appears between the four themes. It means that the students say they have different levels of competences depending on the theme. Themes 1 and 4 are less known by the population of students. But for theme 1, part of the students know it quite well because the standard deviation is big. On the contrary, a large majority of students say they master theme 3. To precise this result, we calculated also the average result for all the different questions of each theme. Figure 4 is showing these results for the theme 3 which has a very high score $(80,9 \%)$ when considered globally. We see that many students say they master many sub-competences of that task which then gets a high score. However other sub-competences are said not to be mastered by $50 \%$ of our students or even $60 \%$. Then according to our competence framework, even if a tool-task is globally considered as well known, it is 
possible that a large population needs to develop his her skills for specific aspects of the task and/or features of the tool.

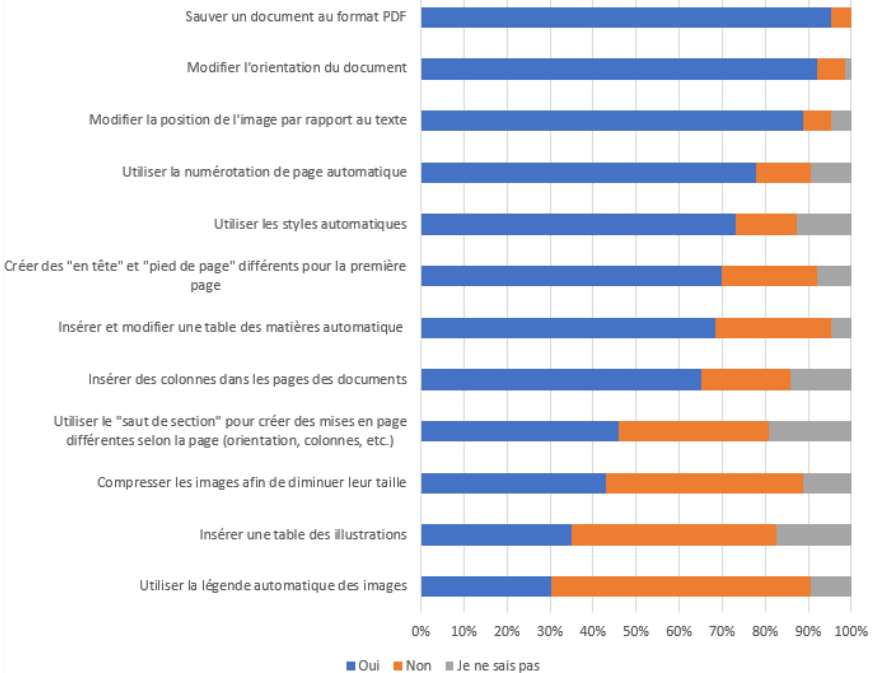

Fig. 4: Answers of 65 students enrolled in the course for the theme "Writing an academic document" (Test of 09.2021)

\subsection{The evaluation of digital skills}

It is usual in a learning system to use a scale with different levels of complexity that can be mastered, or performed, for a competence. These levels are a basis for the evaluation features of the learning system. In this perspective, we organized our competence framework as a rubric in order to allow that the descriptions of the digital skills assembled into our competence framework also serve as evaluation criteria of the skills [23]. We thought about this design because the form of the rubric should also facilitate the creation of the wished evaluative levels. About this point, Rusman and Dirkx insist on the fact that "The levels in a rubric should be parallel in content, which means that if an indicator of quality is discussed in one level, it is discussed in all levels" but, by studying how this was done in many rubrics, they saw that: "The consistency between the dimensions used within the performance indicator descriptions within and across rubrics was quite poor. Most rubrics used words signaling a mastery level only in one or two performance indicators per constituent sub-skills. Also across rubrics, many different verbal qualifiers or signaling words were used to describe the same scales." [24]

A concrete example illustrates this point. In our first attempts to construct a scale of levels, we added a criterion for defining an advanced-expert level for the mastery of a competence: the ability to explain the competence. If somebody does not have this ability, he-she is not at an expert level for this competence. Doing this, we were introducing a new dimension only at the expert level. Then in such a rubric everything looks like that this is not the same competence that is evaluated at the different levels of mastering because all the descriptive dimensions of the competence are not present at all the scale levels. The problem is complex because, as we saw earlier, different dimensions (types of knowledge and of mobilizations) are usually needed to describe a competence. Somebody can say "I am at this level" by reading a multi-dimension descriptor of a given level for a competence. But why did he-she say so? Because of all the dimensions or only a few of them?

Then we prefer now to proceed as follows. We describe a competence as a list of sub-competences where a sub-competence is one type of knowledge and of mobilization according to the model of Paquette [22]. In order to evaluate the competence, we ask the student to select a level on a Likert scale for each of the sub-competences. We have this way "consistency between the dimensions", it means all the sub-competences of the competence are always taken into account. Then the level of mastery of a student for the competence is calculated as a simple percentage of the total of points that he she would have by always selecting the maximum level on the Likert scale for all the sub-competences. Our future work will continue to investigate this evaluation procedure. For example, the final counting could be more sophisticated by introducing a weighting between the different sub-competences of a competence where the weighting is depending on the taxonomical level of difficulty that exists between the different levels of knowledge mobilizations in the model of Paquette [22]. The psycho-cognitive theories show 
that the four mobilization types do not have the same difficulty level: reception is the less difficult, then reproduction, creation and self-management is the most difficult one.

\section{Structure of the course service system}

\subsection{Overview of the service finalities}

The description in the previous sections of this paper highlights the different main functions that need to be operational in our teaching and learning system:

1. Access to pedagogical contents: all students must find explanations about the different learning activities that are usually asked by teachers in university courses;

2. Access to technologies: all students must have an easy access to digital tools that facilitate the realization of the learning activities;

3. Determination of skills to be developed in priority: all students must be able to evaluate themselves on the different digital skills of the competence framework;

4. Access to adapted learning resources: depending on his-her results, one student must be connected with the resources that corresponds to his her individual learning needs;

5. Flexibility of the course access: students of all faculties must be able to enroll easily in the course because the digital skills are transversal and students of all BA years must be able to enroll.

\subsection{The environment of the students' service}

Even though the course is the core of our system, our course service needed a real environment to deliver all its components to students. These components must serve four main finalities in the environment that supports our teaching-learning system: pedagogical, technological, administrative and informative finalities. Pedagogical and technological finalities refer to the two main learning objectives linked to the building of a PLE: assembling digital tools adapted to the student's needs (technological components of PLE) and 2) learning knowledge and know-how about methods and features to be used with such digital tools (educational components of PLE) (cf. section "Global learning objectives"). Table 1 gives a global view of how the different components of the course service are made available either through online platforms or concrete actions on the campus. The two following sections describe then further details, firstly about the pedagogical and technological finalities and, secondly, about the administrative and informative finalities.

Table 1. Components of the courses' system

\begin{tabular}{|c|c|c|}
\hline System component & Main finality & Description \\
\hline \multirow[t]{2}{*}{ Myple web site } & Technological & $\begin{array}{l}\text { Collection of digital tools and features (about } 100 \text { tools } \\
\text { organized in } 15 \text { families) }\end{array}$ \\
\hline & Pedagogical & $\begin{array}{l}\text { Explanation about learning tasks, their steps and the tools that } \\
\text { can help to realize them } \\
\text { ( } 9 \text { learning tasks, everyone with about } 6-7 \text { steps) }\end{array}$ \\
\hline Moodle LMS & Pedagogical & $\begin{array}{l}\text { LMS online learning spaces for courses with } 2 \text { modalities } \\
\text { Thematic presentations about digital skills } \\
\text { Online tests to determine what digital skills to develop in } \\
\text { priority and what exercises to deepen (self-positioning) } \\
\text { Exercises about learning tasks, their steps and the tools that } \\
\text { can help to realize them } \\
\text { Online tests to determine the progression made about the } \\
\text { studied digital skills (learning evaluation) }\end{array}$ \\
\hline Course assessment & Pedagogical & $\begin{array}{l}\text { Online survey to evaluate the acceptance level [25] of } \\
\text { students for the system and for the pedagogical resources }\end{array}$ \\
\hline MyTools days & Informative & $\begin{array}{l}\text { Online videos explain students entering university "how to } \\
\text { start" information about available tools, technological support } \\
\text { services and courses }\end{array}$ \\
\hline Digital Skills web site & Informative & $\begin{array}{l}\text { Web pages where students, all teachers, can find all } \\
\text { objectives, actions, partners, trainings and courses of the Digital } \\
\text { Skills project }\end{array}$ \\
\hline $\begin{array}{lll}\text { "Prestations IT" } & \text { web } \\
\text { pages } & & \end{array}$ & Informative & $\begin{array}{l}\text { Web information service where students can find all } \\
\text { information about institutional tools (description, how to access } \\
\text { them, support contacts, tutorials and other helps of this type, } \\
\text { proposed trainings and courses) }\end{array}$ \\
\hline
\end{tabular}




\begin{tabular}{|l|l|c|}
\hline $\begin{array}{l}\text { Tour of teaching staff and } \\
\text { program's managers }\end{array}$ & Informative & $\begin{array}{c}\text { Meetings to inform about the course offer (competence } \\
\text { framework, learning resources, course modalities) }\end{array}$ \\
\cline { 2 - 3 } & $\begin{array}{l}\text { Technological } \\
\text { and } \\
\text { Pedagogical }\end{array}$ & $\begin{array}{c}\text { Online survey to investigate about digital tools and learning } \\
\text { activities that can be specific to a scientific discipline }\end{array}$ \\
\hline Other actions & Informative & $\begin{array}{l}\text { Series of posters } \\
\text { Collaboration with the university's communication service }\end{array}$ \\
\hline MyuniFR web site & Administration & $\begin{array}{l}\text { Web service where students can register for a course or an } \\
\text { exam }\end{array}$ \\
\hline
\end{tabular}

\subsection{Global scenario and modalities of the course}

To begin this section, we remind you that our global learning objective is to help students to build their PLE and especially aspects linked to digital skills and tools. From this perspective, we explained earlier in this paper that we have two sub-objectives: 1) a student must become able to assemble the digital tools adapted to his $\cdot$ her learning needs (technological components of PLE) and 2) he-she must learn knowledge and know-how about methods and features to be used with such digital tools (educational components of PLE). The two sub-objectives are deeply linked with the two first finalities of our environment (give access to technologies and to pedagogical contents). In order to provide both types of access, we decided to install two different and complementary platforms. Firstly, there is the web site myple (https://elearning.unifr.ch/myple/fr) which gives an access to the two finalities but with a global perspective. Secondly, there is the course with its main platform, a moodle course space.

In myple, the two sub-objectives are targeted with two central ideas: 1) to describe the different steps of the students' learning activities (cf. section "Global learning objectives") and 2) to propose different digital tools that can help the realization of each step. This association allows two types of navigation in myple. A student can enter in the description of a learning activity, see the different steps and then find adapted digital tools for each step. $\mathrm{He}$-she can also enter the global table of the proposed tools and can look what learning activities can be made with the help of a specific tool. But myple maintains a global perspective, and is not a course, as it does not provide detailed learning activities on the exact steps to be taken with a specific digital tool. It is centered, in the task description, on what must be made in each step and on the proposition of digital tools to realize the step. But it is not presenting how to make the task from a software manipulation point of view. With these principles, myple is today a collection of 9 learning activities (separated in 70 steps) and of 97 tools (separated in 15 collections). In order to offer the biggest flexibility, myple is offering its resources in three languages corresponding to the context of universities in Fribourg (French, German and Italian) and all the resources are delivered with a Creative Common license.

On the contrary, the course, which is named "C'est plus facile avec le numérique / Digital geht's einfacher", is more specific and focused on the knowledge and know-how of the realization of different specific learning tasks with specific digital tools and/or features of these tools. It is based on a moodle LMS course space to allow various learning activities. We will now go into more details about the course scenario. At the beginning of the course, students use the self-position test which is a global test with a few questions on all the groups of digital skills of the competence framework. We want this test to be short but to touch every theme of the course. With their results, students can compare if they have more or less knowledge and know-how depending on the different groups of digital skills. With this information, they can decide which skills they need to improve on first. With this selfposition test, we put in action the search of the exact learning needs of the different students. We saw earlier in this paper, when analyzing surveys about the levels of digital skills in the students' population (cf. section "One student, one learning need"), that this search is crucial and that we should offer content flexibility in our course system. The search of the exact learning needs of the different students continues with a flipped classroom scenario. After their choice of digital skills' themes to be developed in priority, we propose to the students to enter a theme by reading and trying to do the exercises related to the theme. Then they tell the teaching staff, via a moodle survey, which exercise is the most difficult and/or more important for them before the class session devoted to that theme. During the session, we do the chosen exercise step by step with the students, answer questions, see in details tricky points, etc. This course step helps them further to determine on what exact topic they need to work more and where more help is needed from the teaching staff. At the end of a theme, a final test is proposed to students to evaluate the progression of their digital skills associated to the theme. In order to validate the course, students constitute a logbook where they insist, for each theme, on what they learned, the difficulties they encountered and the possible transfers, towards other learning situations of their cursus, of the use of digital tools they learned.

Let us note that, in this scenario, the "educational alignment" between the learning objectives, the activities (tests, presentations, exercises, etc.) and the evaluation is obtained thanks to the competence framework that details the context of a student specific activity, made in his $\cdot$ her cursus, and thanks to the competence description method of Paquette that details the psychocognitive aspects of the competence and indicates thus the types of learning activities that we can propose in our course (cf. section "The need for a competence framework"). We really 
confirmed, through the launching of our course, that the "educational alignment" is crucial in order that "étudiant·es et enseignant·es construisent une vision partagée du dispositif de formation et de ses objectifs" [26].

This is especially important because we propose different modalities of our course. The scenario that we just described corresponds to a 3 ECTS course that has the weekly rhythm of a usual class and is proposed as an optional course for the BA students of all the Faculties. In order to bring the maximum of flexibility in the course possible attendance, we are animating it in presence sessions, with a synchronous connection to a Team meeting room so that students can follow also the course in a distance mode. Furthermore, we make video recordings of the sessions in order that they can be followed in an asynchronous way. We made calculations of the video recordings' use done in Autumn 2020 and we obtained this way indications that these videos increased flexibility by giving the possibility to "follow a session" more than one time [27]. For sure we need a more general study about this video use to speak about a real validity of this particular result.

There is also a second modality that will open in February 2022: a self-learning course. This is always in the perspective of flexibility that we propose this modality: in particular, students may only want to follow certain themes, anytime in the year (instead the 3 ECTS course is given in Autumn), do not need any continuous help from teachers because they have a high level of autonomy for learning. Also, the self-learning course can propose more themes than the Autumn course. The self-learning course is based on a Moodle space and begins with a global test on all the themes to allow a student to better determine his her exact learning needs according to our digital skills' competence framework. When the student made a choice for a theme, a few short videos are proposed to prepare the theme. Because no teaching staff is present, each video presents to the students the main ideas of one psychocognitive aspect linked to the theme. Each video shows what are the aims of the aspect, it means what should be realized, and gives examples of realizations (a learning activity done with a digital tool). The student who looks at a video should then know what the wording of the digital skills concretely means. Then a test, dedicated to a theme, is proposed and ask questions to the students about all the psychocognitive aspects linked to the theme. The feedbacks given for each question and the global results of this test guide students towards learning resources that allow to deepen the digital skills, and the exact psychocognitive aspects, that need to be developed. At the end of what he-she did about a theme, the student can do a final evaluative test.

We see that the two learning scenarios for the two course modalities are very similar (self-positioning, priority decision for themes, deepening decided themes with exercises, evaluation of progresses within a theme, remediation and/or final evaluation). Table 2 shows a synthetic view of the learning paths which is proposed to students depending if they enroll the Autumn course or the self-learning modality.

Table 2: Differences between the courses' modalities

\begin{tabular}{|c|c|c|}
\hline Learning steps & Course with registration (classroom) & Self-learning course \\
\hline & Registration & Access to open moodle course \\
\hline self-positioning & Self-position test on all the themes & Self-position test on all the themes \\
\hline $\begin{array}{l}\text { priority decision for } \\
\text { themes }\end{array}$ & $\begin{array}{l}\text { Access to resources on a theme } \\
\text { (according to the course schedule) } \\
\text { Students with low score for a theme are } \\
\text { advised to follow the related course } \\
\text { session } \\
\text { Students with high score for a theme are } \\
\text { advised to work at their rhythm with the } \\
\text { related resources }\end{array}$ & $\begin{array}{l}\text { Access to resources on a theme } \\
\text { (without a schedule) }\end{array}$ \\
\hline preparation on a theme & $\begin{array}{l}\text { Reading of exercises } \\
\text { Vote for the most needed exercise }\end{array}$ & $\begin{array}{l}\text { Videos on the theme } \\
\text { Position test on the theme }\end{array}$ \\
\hline $\begin{array}{l}\text { deepening decided } \\
\text { themes and exercises }\end{array}$ & $\begin{array}{l}\text { Voted exercise is done in course } \\
\text { Discussion, questions/answers }\end{array}$ & Exercises and other resources \\
\hline $\begin{array}{l}\text { evaluation of } \\
\text { progresses within a } \\
\text { theme }\end{array}$ & Evaluation test on the theme & Evaluation test on the theme \\
\hline $\begin{array}{l}\text { remediation and/or } \\
\text { final evaluation }\end{array}$ & $\begin{array}{l}\text { Final evaluation of a Logbook (what } \\
\text { learnings? what obstacles? what possible } \\
\text { transfers?) }\end{array}$ & $\begin{array}{l}\text { Remediation on the basis of the test } \\
\text { feedbacks } \\
\text { Possible certificate (badge system) }\end{array}$ \\
\hline
\end{tabular}

\subsection{Information and administrative actions about the course}

Table 1 shows the list of actions that are informing the community about the course offer. Let us detail here below the main actions made for students and teachers.

For students: 
- Mytools days: As soon as they enroll a cursus, the university of Fribourg proposes to students a web site where online videos explain "how to start" information about available tools, technological support services and courses (directly linked to the present paper: myple and the course). Let us note that a "Faculty day" completes the Mytools days for a presentation about all the cursus. These actions are done just before the back to school week in September and, at this period of the university calendar, there is also a posters' campaign in all the university buildings to draw students' attention to the courses offered by the digital skills project.

- Web sites: Two web sites deliver information to students, and also to all the university community, about: 1) the digital skills project and 2) all the computer tools and services which are available for the university community:

- The web site of the digital skills project (https://www.unifr.ch/digitalskills/fr/) informs about the partnership of the project, the trainings offered to teachers and to students, other actions dedicated to the institution.

- The web pages informing about the computer tools and services are called "Pages Prestations IT" and, directly linked to the present paper, there are the category "Enseignement et Apprentissage" (https://www.unifr.ch/it/fr/enseignement-and-apprentissage/) and the category "Formations" (https://www.unifr.ch/it/fr/formations/). The digital skills project was an opportunity to get back to the necessary types of information to be delivered to the community about the tools and services [28].

For teachers:

- If they are convinced that digital skills are crucial for their students, they can publicize our course to their students who can then can enroll our course. To do so, they need information about our offer: what are exactly the targeted learning objectives, in terms of digital skills (competence framework)? What learning resources and learning activities do we propose? What course modalities are proposed?

- We want to inform them in particular about the possibility of "digital skills interventions" in their own courses. If they are proposing learning activities in their courses where digital skills and tools are important, they can refer their students to myple or they can contact us to make their students entering the self-learning modality of our course, with a few specific added resources.

Last but not least, the administrative system was ameliorated in order to facilitate the registration of students in all the courses of the Digital Skills project. In the web service MyuniFR, in a first step, we were using the "complementary course" course status where optional courses are listed. If a student is enrolled in a cursus, he-she finds there all the optional courses that he she can attend. Usually such optional courses are proposed by teachers of other disciplines. The result was that our digital skills courses were lost in all the other propositions and then mostly invisible. In a second step, we added an upper category, in the "complementary course" list. The attention of the students was then attracted as soon as they were entering the "complementary course" list for choosing one optional course.

\section{Conclusions and perspectives}

In this paper, we analyzed the different steps of the innovation pursued to design and implement a course service that aims to develop the digital skills of BA students. We began showing how this training action fits into the current effort of the higher education institutions to better meet the needs of students. Today digital skills are increasingly necessary for success in both the learning activities of their academic careers and the work activities of their professional lives. The student's personal learning environment must therefore include digital components and universities can/should support this development.

We then analyzed how to respond to this challenge. Two main results emerge from this analysis. Firstly, a digital competence framework is needed for the university learning context. It should help to clearly define what types of digital skills are needed and/or emerging in current learning practices related to university courses. It should also help create a common language that improves understanding between teachers and students working together in a learning activity involving digital skills. Finally, for each specific digital skill, a framework can provide descriptions that are based on the different psycho-cognitive aspects (knowledge and know-how) of the skill and, therefore, helps in the design of learning activities and resources linked to this specific digital skill. Secondly, surveys in the student population have indicated that we need to better understand the individual profiles that exist in the student population regarding digital skills. What experience do they have, prior to college, regarding the digital skills of an academic framework? What digital experience do they develop during their academic career? Today, many students, from all five years of BA and MA, report feeling unprepared for digital skills. In addition, students report different levels of mastery depending on the digital skill. Finally, a student may only master some and not all psychocognitive aspects of a skill. 
Our project team therefore decided to transform generic competence frameworks, whose validity is recognized (e.g. DigComp, the EU framework), into a specific framework adapted to our university learning context in order to offer a flexible service of courses and/or training modules for all BA students. The course and its resources are delivered and facilitated using a Moodle platform. The student can first choose between two course modalities (with a class or a self-study organization) where a personalized learning path is proposed through a global structure of thematic modules. A self-position test is used to prioritize the student's skill development needs and the student is then guided to further personalize his her use of the proposed learning resources. At the end of a module, a test helps the student to evaluate how the digital aspects of his her PLE evolved. Informative actions (launch day events, websites, posters, flyers, mailings, etc.) and administrative actions (web-based registration service) play an important role in our course service.

The course is now open in its "classroom" modality. The "self-study" modality will be opened very soon. From now on, a perspective of work can be to develop an assessment of the course to investigate further how the students use the course: Which modalities interest them the most and why? What learning resources are used most? How effective is the adaptation to their learning needs? Are the self-position and evaluation tests accurate enough? What digital skills are students developing? To answer these questions, an acceptance questionnaire will be used as well as the final work of the students registered in the "classroom" modality of the course. In addition, we are also considering using the learning analytics functions of Moodle. Another future perspective would be a comparison with other courses and trainings implemented in the framework of the Digital Skills program of Swissuniversities. The Eduhub community (https://www.eduhub.ch/) could be one of the supports for such an activity.

\section{Bibliography}

[1] Université de Fribourg, «C'est plus facile avec le numérique », 2021. https://www.unifr.ch/digitalskills/fr/student/etudier-avec-numerique.html (consulté le nov. 19, 2021).

[2] Swissuniversities, «P-8 "Renforcement des digital skills dans l'enseignement” », 2021. https://www.swissuniversities.ch/fr/themes/digitalisation/digital-skills (consulté le nov. 19, 2021).

[3] European Commission, «The Digital Education Action Plan (2021-2027)», 2021. https://ec.europa.eu/education/education-in-the-eu/digital-education-action-

plan en\#: : text=The $\% 20$ Digital $\% 20$ Education $\% 20$ Action $\% 20$ Plan $\% 20 \% 282021$ -

$2027 \% 29 \% 20$ outlines $\% 20$ the, action $\% 20$ for $\% 20$ stronger $\% 20$ cooperation $\% 20$ at $\% 20$ European $\% 201$ evel $\% 20 \mathrm{t}$ o (consulté le nov. 22, 2021).

[4] DQ Institute, «DQ Global Standards Report 2019 Common Framework for Digital Literacy, Skills and Readiness », DQ Institute, 2019. https://www.dqinstitute.org/wpcontent/uploads/2019/11/DQGlobalStandardsReport2019.pdf (consulté le nov. 19, 2021)

[5] M. Prensky, « Digital Natives, Digital Immigrants », On the Horizon, vol. 9, n 5, 2001.

[6] A. Littlejohn, H. Beetham, et L. McGill, «Digital literacies as situated knowledge practices. Academics' influence on learners' behaviours », in Literacy in the digital university: Critical Perspectives on learning, scholarship, and technology, R. Goodfellow et M. R. Lea, Éd. Abingdon: Routledge, 2013, p. 126-136.

[7] C. Jones, "The digital university. A concept in need of definition ", in Literacy in the digital university: Critical Perspectives on learning, scholarship, and technology, R. Goodfellow, L. Goodfellow, et R. Mary, Éd. Abingdon: Routledge, 2013, p. 162-172.

[8] J.-H. Morin et L. Moccozet, «Build to think, build to learn: What can fabrication and creativity bring to rethink (higher) education? ", ITM Web Conf., vol. 38, p. 02004, 2021, doi: 10.1051/itmconf/20213802004.

[9] T. Shopova, "Digital literacy of students and its improvement at the university ", Journal on Efficiency and Responsibility in Education and Science, vol. 7, $\mathrm{n}^{\circ}$ 2, Art. $\mathrm{n}^{\circ}$ 2, juill. 2014, doi: 10.7160/eriesj.2014.070201.

[10] S. Berghaus et A. Back, «Disentangling the Fuzzy Front End of Digital Transformation: Activities and Approaches », Seoul, déc. 2017, p. 1-17. Consulté le: nov. 19, 2021. http://aisel.aisnet.org/cgi/viewcontent.cgi?article=1185\&context=icis2017

[11] A. M. O. Agba, S. I. Ocheni, et M. S. Agba, «COVID-19 and the World of Work Dynamics: A Critical Review ", Journal of Educational and Social Research, sept. 2020, https://www.richtmann.org/journal/index.php/jesr/article/view/12231

[12] G. Attwell, « Personal Learning Environments - the future of eLearning? », eLearning papers, vol. 2, $\mathrm{n}^{\circ}$ 1, 2007.

[13] S. Carretero, R. Vuorikari, et Y. Punie, «DigComp 2.1: The Digital Competence Framework for Citizens with eight proficiency levels and examples of use », European Commission EUR 28558 EN, 2017. [En ligne]. http://publications.jrc.ec.europa.eu/repository/bitstream/JRC106281/web-digcomp2.1pdf_(online).pdf

[14] JISC team, « Developing digital literacies. Full guide », 2014. https://www.jisc.ac.uk/full-guide/developing$\underline{\text { digital-literacies }}$ 
[15] E. Van Laar, A. J. A. M. Van Deursen, J. A. G. M. Van Dijk, et J. De Haan, « The relation between 21stcentury skills and digital skills: A systematic literature review », Computers in Human Behavior, vol. 72, p. 577-588, juill. 2017, doi: 10.1016/j.chb.2017.03.010.

[16] Centre NTE DIT, « Le cours-ateliers "C'est plus facile avec le numérique" ». Université de Fribourg, mai 2021. https://drive.switch.ch/index.php/s/bJIHDRbjHUC7luu

[17] G. Le Boterf, De la compétence à la navigation professionnelle. Paris: Editions d'Organisation, 1999.

[18] G. Scallon, L'évaluation des apprentissages dans une approche par compétences. Québec - Bruxelles : De Boeck, 2004.

[19] G. Scallon, Des savoirs aux compétences : exploration en évaluation des apprentissages. Louvain-la-Neuve : De Boeck, 2015.

[20] Ng, Wan. « Can we teach digital natives digital literacy? », Computers \& Education, vol. 59, n 3: 1065-1078, 2012.

[21] H. Platteaux et L. Moccozet, « Comment transformer un référentiel de littératie numérique en un outil de médiation pédagogique? Analyse pratique. », Revue hybride en éducation de l'Université du Québec à Chicoutimi, $\mathrm{n}^{\mathrm{O}}$ Numéro spécial sur les compétences du 21e siècle, 2021 (à paraître).

[22] G. Paquette, Modélisation des connaissances et des compétences. Un langage graphique pour concevoir et apprendre. Sainte-Foy (Québec) : Presses de l'Université du Québec, 2002.

[23] H. Platteaux, E. Salietti, et L. Molteni, « The design of a rubric for defining and assessing digital education skills of higher education students », European Journal of Open, Distance and E-Learning, $\mathrm{n}^{\circ}$ Best of EDEN2018 Special Issue, p. 140-151, 2019.

[24] E. Rusman et K. Dirkx, " Developing Rubrics to Assess Complex (Generic) Skills in the Classroom: How to Distinguish Skills' Mastery Levels? », Practical Assessment, Research \& Evaluation, vol. 22, n 12,2017 , http://pareonline.net/getvn.asp? $v=22 \& n=12$

[25] R. Scherer, F. Siddiq, et J. Tondeur, « The technology acceptance model (TAM): A meta-analytic structural equation modeling approach to explaining teachers' adoption of digital technology in education », Computers \& Education, vol. 128, p. 13-35, janv. 2019, doi: 10.1016/j.compedu.2018.09.009.

[26] D. Peraya, B. Charlier, et N. Deschryver, «Une première approche de l'hybridation Étudier les dispositifs hybrides de formation. Pourquoi ? Comment? », Education et Formation, n ${ }^{\circ}$ e-301, p. 15-34, 2014.

[27] H. Platteaux, «Les étudiant·es utilisent-ils les enregistrements vidéos des cours ? », Le blog du Centre NTE, février 2021. https://nte.unifr.ch/blog/2021/02/22/les-etudiant $\%$ c $2 \%$ b 7 es-utilisent-ils-les-enregistrementsvideos-des-cours/ (consulté le nov. 29, 2021).

[28] Centre NTE DIT, «Développement des outils institutionnels / Road Map (rapport du projet DigitalSkills@UniFR) », University de Fribourg. https://drive.switch.ch/index.php/s/SgBOqYSjjirXera 